\title{
The "Globularization Hypothesis" of the Language-ready Brain as a Developmental Frame for Prosodic Bootstrapping Theories of Language Acquisition
}

\author{
Aritz Irurtzun * \\ CNRS, IKER (UMR 5478), Bayonne, France
}

In recent research (Boeckx and Benítez-Burraco, 2014a,b) have advanced the hypothesis that our species-specific language-ready brain should be understood as the outcome of developmental changes that occurred in our species after the split from Neanderthals-Denisovans, which resulted in a more globular braincase configuration in comparison to our closest relatives, who had elongated endocasts. According to these

OPEN ACCESS

Edited by:

Cedric Boeckx,

Catalan Institute for Research and Advanced Studies (ICREA) and

Universitat de Barcelona, Spain

Reviewed by:

Silvia Martínez Ferreiro,

University of Barcelona and University of Groningen, Spain

Monika T. Molnar,

Basque Center on Cognition, Brain and Language, Spain

${ }^{*}$ Correspondence: Aritz Irurtzun aritz.irurtzun@iker.cnrs.fr

Specialty section: This article was submitted to Language Sciences, a section of the journal

Frontiers in Psychology

Received: 30 July 2015 Accepted: 10 November 2015 Published: 09 December 2015

Citation: Irurtzun A (2015) The "Globularization Hypothesis" of the Language-ready Brain as a Developmental Frame for Prosodic Bootstrapping Theories of

Language Acquisition

Front. Psychol. 6:1817. doi: 10.3389/fpsyg.2015.01817 authors, the development of a globular brain is an essential ingredient for the language faculty and in particular, it is the centrality occupied by the thalamus in a globular brain that allows its modulatory or regulatory role, essential for syntactico-semantic computations. Their hypothesis is that the syntactico-semantic capacities arise in humans as a consequence of a process of globularization, which significantly takes place postnatally (cf. Neubauer et al., 2010). In this paper, I show that Boeckx and Benítez-Burraco's hypothesis makes an interesting developmental prediction regarding the path of language acquisition: it teases apart the onset of phonological acquisition and the onset of syntactic acquisition (the latter starting significantly later, after globularization). I argue that this hypothesis provides a developmental rationale for the prosodic bootstrapping hypothesis of language acquisition (cf. i.a. Gleitman and Wanner, 1982; Mehler et al., 1988, et seq.; Gervain and Werker, 2013), which claim that prosodic cues are employed for syntactic parsing. The literature converges in the observation that a large amount of such prosodic cues (in particular, rhythmic cues) are already acquired before the completion of the globularization phase, which paves the way for the premises of the prosodic bootstrapping hypothesis, allowing babies to have a rich knowledge of the prosody of their target language before they can start parsing the primary linguistic data syntactically.

Keywords: globularization, prosodic bootstrapping, language development, language acquisition, postnatal development

\section{INTRODUCTION: THE GLOBULARIZATION HYPOTHESIS}

According to a recent article in this journal by Boeckx and Benítez-Burraco (2014a), "much work in neurolinguistics has unintentionally emphasized the externalization component of language, since morpho-phonology is perhaps the easiest aspect to single out linguistic tasks, even if the word "syntax" was said to be the target of the relevant works. In so doing, work on neuroimaging biased 
the results toward the Broca-Wernicke model, and all too quickly attributed "syntax" to Broca's area." In contrast, Boeckx and Benítez-Burraco (2014a,b) have advanced the hypothesis that our species-specific language-ready brain (a brain which is suited for acquiring natural languages) should be understood as the outcome of developmental changes that occurred in our species after the split from Neanderthals-Denisovans, and which resulted in a more globular braincase configuration in comparison to our closest relatives, who had elongated endocasts. They propose that even if factors like brain lateralization are important, the development of a globular brain is at the outset of our language faculty, and in particular, it is the centrality of the thalamus in a globular brain that allows its modulatory or regulatory role, essential for syntactico-semantic computations (cf. i.a. Wahl et al., 2008).

Inportantly, globularization takes place postnatally (cf. Lieberman et al., 2002; Neubauer et al., 2010; Gunz et al., 2012), therefore, according to Boeckx and Benítez-Burraco's hypothesis, even if innately specified, the combinatorial syntactic ability of humans is not innate stricto sensu, but the outcome of a postnatal developmental phase. After globularization a new brain configuration is obtained whereby the thalamus occupies a central position (and a central role). As Boeckx and Benítez-Burraco (2014a) put it, "a proper characterization of the language-ready brain that does not recognize a central role to the thalamus is unlikely to be correct, for it would miss the critical engagement of the thalamus in regulating cortical activity. By providing low-frequency oscillations capable of embedding higher-frequency oscillations across distant brain regions, the thalamus provides the crucial regulation needed to form the sort of meaningful cross-modular conceptual structures that are characteristic of language."

In this paper I discuss the developmental dimension of Boeckx and Benítez-Burraco's hypothesis and relate it to one of the most prominent hypotheses in early language acquisition studies; the "prosodic bootstrapping hypothesis" (cf. i.a. Mehler et al., 1988; Christophe et al., 2003; Bernard and Gervain, 2012; Gervain and Werker, 2013; Langus and Nespor, 2013).

The argument is presented as follows: Section 2 gives a brief overview of the development of the ability for phonological discrimination in human infants (an essential prerequisite for the identification and acquisition of the prosodic patterns of the target language). Section 3 presents the basic tenets of the prosodic bootstrapping hypothesis (a hypothesis that claims that language-acquiring children use prosody as a guide for inferring the basic syntactic pattern of their target language). Last, Section 4 argues for a natural combination of the globularization hypothesis and the prosodic bootstrapping hypothesis. In a nutshell, the globularization hypothesis proposes that the ability for syntactic computations is not innate, but that it rather develops after the postnatal globularization phase. In contrast, as the studies of early phonological development show, babies a few moths old have already a rich knowledge of the prosodic patterns of their target language. Therefore, and in line with the prosodic bootstrapping hypothesis, languageacquiring babies will be able to use their early-acquired prosodic knowledge as a guiding principle for inferring the syntax of their target language the moment the syntactic ability develops.

\section{EARLY PHONOLOGICAL ABILITIES IN HUMAN INFANTS}

Some essential ingredients for language acquisition are already present at birth. Since the seventies, a wide range of studies have shown infants' capacity for very early phonological parsing and discrimination (for an overview, see Panneton and Newman, 2012; Vihman, 2014). For instance, Eimas et al. (1971) found that infants as young as 1 month of age are able to discriminate the voice onset time (VOT) of synthetic stop consonants like /p/-/b/ in a manner approximating adult categorical perception. Similar results were obtained by Moffitt (1971) with 20- to 24-week-old infants in a study attesting the discrimination in place of articulation of different consonants. Given the limited exposure of newborn infants to speech, these results suggest that this categorical perception in a linguistic mode may be innate, and in the general debate on language nature vs. nurture, scholars such as J. Mehler have built upon these early capacities to argue for innatist "selectionist" theories of language learning whereby the baby "learns" her target language by "forgetting" others (cf. i.a. Mehler, 1974; Mehler and Dupoux, 1990).

What is more, the earliest fetal responses to auditory stimuli are reported at 19 weeks of gestation, long before the development of the fetal ear is complete (cf. Hepper and Shahidullah, 1994; Abdala and Keefe, 2012), and effects of very early auditory categorization have also been found in utero: a number of experiments have shown that third-trimester fetuses' auditory experience can influence their postnatal auditory preferences: newborns tend to quiet in response to their mothers' voice (and touch), Marx and Nagy (2015), and they also tend to prefer their mother's voice over other female's voice (cf. Mehler et al., 1978; DeCasper and Fifer, 1980; Fifer, 1981; Querleu et al., 1984; Spence and DeCasper, 1987; Ockleford et al., 1988; Hepper et al., 1993) ${ }^{1}$. Besides, as reported by DeCasper and Spence (1986), newborns also tend to be more reinforced by the audition of speech passages they heard in utero over passages they were not exposed to (and they can remember them for over a month; Granier-Deferre et al., 2011). Finally, Mampe et al. (2009) provide evidence that even the cry melodies of newborns of around 3 days of age are shaped in accordance with the intonational contours of the language they were exposed to prenatally (German vs. French). All this conforms evidence of a very early ability for the discrimination and memorization of complex sounds in newborn infants.

Regarding prosody and rhythm, there is ample evidence that newborns also have the ability for discrimination between inputs varying in different suprasegmental properties (see i.a. Morse, 1972; Olsho et al., 1982; Mehler et al., 1988; Karzon and Nicholas, 1989; Shahidullah and Hepper, 1994; Sansavini et al., 1997; Nazzi et al., 1998a,b; Carral et al., 2005). In

${ }^{1}$ However, infants do not seem to show preferences for their father's voice (cf. Ward and Cooper, 1999). 
particular, studies like Nazzi et al. (1998a) show that babies can discriminate between languages pertaining to different rhythmic classes [such as Japanese (mora-timed) or British English (stress-timed)] when exposed to low-pass filtered speech signals. The setting in this type of experiment shows that babies discriminate between rhythmic classes because by lowpass filtering (e.g., under $400 \mathrm{~Hz}$ ) the speech signal, it gets a dramatic degradation of its phonemic content (i.e., the vast majority of its formant structure is removed), while it retains its rhythmic structure. Other studies employing this type of low-pass filtered stimuli (like Byers-Heinlein et al., 2010) provide evidence that language discrimination in neonates which were surrounded by a bilingual environment prenatally is robust, and that that language preference reflects previous listening experience (see also Gervain and Werker, 2013; Molnar et al., 2014a,b). Besides, other types of studies show that at $41 / 2$ months babies tend to listen longer to speech samples that include prosodic pauses corresponding to syntactic units, as opposed to speech samples with pauses that break syntactic units (cf. Jusczyk and Nelson, 1996 and references therein).

All these results are to be framed in the fast (pre- and post-natal) development of the basic structures for sound discrimination in humans (whereby infants already possess an adult-like dedicated neuronal network for phonological processing at 3 months of age (cf. Dehaene-Lambertz and Baillet, 1998 as well as Peña et al., 2003; Dehaene-Lambertz et al., 2006 or Dubois et al., 2015) ${ }^{2}$.

Interestingly, however, early acoustic discrimination is not a human-specific ability, for it is also observed in a wide variety of other animals like guinea pigs (Vince, 1979), sheep (Vince et al., 1982) or chinchillas (Kuhl and Miller, 1975), and discrimination of languages of different prosodic types is also mastered by different species like cotton-top tamarins (cf. Ramus et al., 2000), or rats (cf. Toro et al., 2003).

Nonetheless, there is a growing amount of literature arguing that human infants go well beyond mere acoustic patternrecognition and learning; evidence suggests that babies use the prosodic patterns of their target language in order to infer the syntactic structure underneath them in a sort of "reverse engineering." That is, part of the knowledge obtained by babies from categorical perception is restricted to a specific area (say, learning of the vowel space or the consonantal inventory of the target language), but a subpart of the learning obtained with this innate capacity is more consequential: learning the tunes of the surrounding language helps the child making informed guesses about the syntactic structure of the language [this is so because the prosodic pattern of a language partially reflects the syntactic structure underneath (cf. Gussenhoven, 2004; Truckenbrodt, 2007; Selkirk, 2011)]. This is in a nutshell the proposal of the "prosodic bootstrapping hypothesis."

${ }^{2}$ See Telkemeyer et al. (2009) for a near-infrared spectroscopy and EEG study showing that a right hemispheric lateralization for slow acoustic modulations (characteristic of prosodic features) is present at birth (see also Telkemeyer et al., 2011).

\section{THE "PROSODIC BOOTSTRAPPING" HYPOTHESIS}

Prosody and rhythm are essential ingredients of natural language (cf. i.a. Brentari, 1999; Gussenhoven, 2004; Pfau and Quer, 2010) and a growing number of scholars argue that they have a close connection with other aspects of human cognition like musical aesthetics and computation, or our mathematical abilities (cf. i.a. Rebuschat et al., 2011; Arbib, 2013; Asano and Boeckx, $2015)^{3}$. Current literature converges in the idea that beyond the early ability for prosodic discrimination, "prosodic segmentation abilities emerge crosslinguistically some time around 8 months" (Nazzi et al., 2006, p. 296).

The rationale under the rapid acquisition of prosody could be seen as emerging from the combination of the following two factors:

(i) First, babies develop very early the necessary brain structures for adequately parsing acoustic inputs-and in particular human language inputs (see references above and Pang and Taylor, 2000, among others)-, and a growing number of works is emphasizing the natural "tuning up" between speech rhythm and endogenous oscillatory auditory cortical properties (cf. i.a. Drullman et al., 1994; Smith et al., 2002; Lakatos et al., 2005; Giraud et al., 2007; VanRullen and Dubois, 2011; Leong, 2012) ${ }^{4}$. In particular, neuronal oscillatory activity in the Theta band $(3-7 \mathrm{~Hz})$ is thought to track syllable patterns, whereas slower oscillations in the Delta band $(1-3 \mathrm{~Hz})$ track phrasal and intonational patterns (cf. Giraud and Poeppel, 2012; Peelle and Davis, 2012). Ghazanfar and Takahashi (2014) have argued that the same oscillatory cycles are present in macaques' lip smacking, suggesting that "lip smacking may have been an ancestral expression linked to vocal output to produce the original rhythmic audiovisual speech-like utterances in the human lineage" (see also Fitch, 2013; Martins and Boeckx, 2014, for discussion, as well as Theofanopoulou, 2015, for a recent evo-devo hypothesis according to which the myelination of the Corpus Callosum, brain asymmetry and globularity "are conjectured to make up the angles of a co-evolutionary triangle that gave rise to our language-ready brain").

(ii) Second, children are exposed to a very particular input (infant-directed speech), which has very specific linguistic and paralinguistic properties. Following the traditional view, infant-directed speech has a set of hyperarticulated features that help the child develop her linguistic capacities and acquire her language. For instance, infant-directed speech is typically associated with an exaggerated pitch, which is covered with emotional prosody to capture the child's attention (cf. i.a. Fernald, 1984; Cooper and Aslin, 1989; Fernald and Mazzie, 1991; Katz et al., 1996).

\footnotetext{
${ }^{3}$ See also Wang et al. (2015) for a proposal about the brain areas in charge of the human-specific ability for the integration of multiple features in abstract pattern learning.

${ }^{4}$ A reviewer rightly notes that these studies are performed with adult subjects, not with babies. Indeed, we need infant studies to assess the development of rhythmic brain oscillations (see Musacchia et al., 2015, for some of the first reported evoked oscillations analyses in infants).
} 
Actually, a recent study of the spectral amplitude modulation in the speech rhythm shows that (Australian English) infantdirected speech "exaggerates" the synchronization between syllable-rate modulations and stress-rate modulations, whereas adult-directed speech is dominated by syllable-time modulations. This is taken as evidence showing that infant-directed speech "is primarily stress-dominant, which could "tune" the infant brain toward stress-based speech segmentation-an adaptive strategy for boot-strapping early language learning" (Leong et al., 2014). Such infant-directed speech hyperarticulations are taken to help the child acquire the relevant phonological distinctions in her language (Kuhl et al., 1997; Cristia, 2013), a knowledge that is mostly acquired during the first year of life (cf. i.a. Kuhl et al., 1992; Werker and Tees, 2002) ${ }^{5}$. Incidentally, it has to be noted that recent studies have shown that the characteristic "hyperarticulation" of infant-directed speech may be restricted to these suprasegmental levels of prosody, given that rather than hyperarticulated, phonemic contrasts can be hypoarticulated in infant-directed speech, i.e., that mothers hyperarticulate their infant-directed speech in prosodic aspects, but in segmental aspects mothers may "speak less clearly to infants than to adults" (cf. Martin et al., 2014).

Now, several authors have proposed that the early acquired rhythmic properties of languages are not idiosyncratic and isolated properties, but rather that they are strongly correlated with the particular syntactic properties of the particular languages (i.e., that there are correlations between rhythmic patterns and syntactic patterns in that languages tend to cluster with the same rhythmic and syntactic properties, conforming linguistic typologies). Furthermore, the explanation of this typological clustering is proposed to derive from the fact that rhythmic patterns serve to bootstrap or catalyze the acquisition of the specific syntactic patterns of each language (cf. i.a. Mehler et al., 1988; Christophe et al., 2003; Bernard and Gervain, 2012; Gervain and Werker, 2013; Langus and Nespor, 2013) ${ }^{6}$. In particular, a number of authors have proposed that the relative order between heads and their complements strongly correlates with the rhythmic type of the language. A number of experiments have shown that languages whose correlates of phrasal accent are increases in duration and intensity tend to be head-initial (with a Verb-Object word order) whereas languages that realize stress through a combination of higher pitch and intensity (and possibly also duration) tend to be head-final (with an ObjectVerb word order $)^{7}$. This generalization is known as the iambictrochaic law' (cf. i.a. Hayes, 1995; Nespor et al., 2008; Shukla and Nespor, 2010), which is taken to be a basic law of grouping based on general auditory perception (i.e., not specific to language) that states that units (language or music) that differ in intensity

\footnotetext{
${ }^{5}$ In fact, lack of adequate acquisition of the phonology of the target language can generate disorders such as dyslexia (Paulescu et al., 2001; Goswami, 2011; Saralegui et al., 2014; see also Benítez-Burraco, 2013)

${ }^{6}$ Donegan and Stampe $(1983,2004)$ have even proposed a "holistic typology" based on rhythmic grounds in order to account for the polarized structural divergence of languages like Munda and Mon Khmer.

${ }^{7}$ In turn, speakers of languages with different rhythmic patterns like English vs. Japanese tend to behave differently in the way in which they group nonlinguistic stimuli (Iversen et al., 2008).
}

tend to be grouped as constituents in which the most prominent element comes first, and units that differ in duration are grouped as constituents in which the most prominent element comes last ${ }^{8}$. As Nespor et al. (2008) put it, "if [their] proposal is on the right track, one of the basic properties of syntax can be learned through a general mechanism of perception."

This line of reasoning is reinforced by recent studies such as Gordon et al. (2015) suggesting that there is a correlation between rhythm perception skills and morpho-syntactic production in children with typical language development (and note also that a strong association between reading skills and meter perception and rhythm processing has been found; Flaugnacco et al., 2014; Leong and Goswami, 2014). Likewise, studies like Zumbansen et al. (2014), Leong and Goswami (2014) report the beneficial effects of both pitch and rhythm in the clinical therapy for patients with Broca's aphasia.

In the next section, I argue for the natural combination of the "globularization" and "prosodic bootstrapping" hypotheses.

\section{SYNTHESIS: THE "GLOBULARIZATION HYPOTHESIS" AS A DEVELOPMENTAL FRAME FOR THE "PROSODIC BOOTSTRAPPING" HYPOTHESIS}

Let us focus on the two main ideas that we have seen so far, which are that (i) according to the "globularization hypothesis" of Boeckx and Benítez-Burraco (2014a,b), the postnatal globularization of the brain is an essential ingredient for the development of our syntactic capacities, and that (ii) according to the "prosodic bootstrapping hypothesis" of Mehler et al. (1988), Christophe et al. (2003), Bernard and Gervain (2012), Gervain and Werker (2013), Langus and Nespor (2013) and others, children use prosody in order to infer the syntactic pattern of the language they are acquiring.

The combination of these two hypotheses brings about an interesting picture regarding language acquisition: it leaves room for a delay in the acquisition of syntax with respect to prosody. If the "globularization hypothesis" is correct, syntactic capacities develop some months after birth and if the "prosodic bootstrapping hypothesis" is correct, children use prosody as a guiding principle for acquiring syntax. That is, babies may have a rich knowledge of prosody (as pure melodic patterns, unrelated to any syntactic structure) by the moment they develop the capacity to start parsing syntax. Crucially, all the data discussed in Sections 2 and 3 point in that direction: after some months of pre- and post-natal experience with linguistic input, babies have a fairly good knowledge of the prosodic properties of the language(s) spoken around them, this knowledge being arguably well established by the time they develop the structures necessary for parsing syntax. Therefore, babies will be able to use all this phonological knowledge as a guiding principle to discover the syntax behind the acoustic

\footnotetext{
${ }^{8}$ In a recent study de la Mora et al. (2013) observed that rats group sequences based on pitch variations as trochees, but that they do not group sequences varying in duration as iambs.
} 
signals. As a matter of fact, the hypothesis by Boeckx and BenítezBurraco $(2014 \mathrm{a}, \mathrm{b})$ can provide a developmental rationale for the prosodic bootstrapping hypothesis of early language acquisition. Given Boeckx and Benítez-Burraco's hypothesis, it is natural for a rich phonological knowledge to be established before the syntactic ability develops, for the necessary mechanisms for phonological acquisition are present at birth. Then, endowed with a rich prosodic knowledge, language-acquiring children will be able to use it as a bias for hypothesizing the syntactic pattern of the target language (which in a Bayesian model could take the form of an informed prior). In an nutshell, the prosodic bootstrapping hypothesis claims that beyond the observed typological correlation between prosodic and syntactic patterns, there is a causal developmental connection between them: babies use prosody to guess the syntactic pattern of their target language and my proposal is that the globularization hypothesis provides a natural developmental frame for the prosodic bootstrapping hypothesis, for it presents

\section{REFERENCES}

Abdala, C., and Keefe, D. H. (2012). "Morphological and functional ear development," in Human Auditory Development, eds L. A. Werner, R. R. Fay, and A. N. Popper (Dordrecht: Springer), 19-60.

Arbib, M. A., editor (2013). Language, Music, and the Brain: A Mysterious Relationship. Cambridge; London: MIT Press.

Asano, R., and Boeckx, C. (2015). Syntax in language and music: what is the right level of comparison? Front. Psychol. 6:942. doi: 10.3389/fpsyg.2015.00942

Benítez-Burraco, A. (2013). "Genetics of language: roots of specific language deficits," in The Cambridge Handbook of Biolinguistics, eds C. Boeckx and K. K. Grohmann (Cambridge: Cambridge University Press), 375-412.

Bernard, C., and Gervain, J. (2012). Prosodic cues to word order: what level of representation? Front. Psychol. 3:451. doi: 10.3389/fpsyg.2012.00451

Boeckx, C., and Benítez-Burraco, A. (2014a). Globularity and language-readiness: generating new predictions by expanding the set of genes of interest. Front. Psychol. 5:1324. doi: 10.3389/fpsyg.2014.01324

Boeckx, C., and Benítez-Burraco, A. (2014b). The shape of the language-ready brain. Front. Psychol. 5:282. doi: 10.3389/fpsyg.2014.00282

Brentari, D. (1999). A Prosodic Model of Sign Language Phonology. Cambridge; London: MIT Press.

Byers-Heinlein, K., Burns, T. C., and Werker, J. F. (2010). The roots of bilingualism in newborns. Psychol. Sci. 21, 343-348. doi: 10.1177/0956797609360758

Carral, V., Huotilainen, M., Ruusuvirta, T., Fellman, V., Näätänen, R., and Escera, C. (2005). A kind of auditory 'primitive intelligence' already present at birth. Eur. J. Neurosci. 21, 3201-3204. doi: 10.1111/j.1460-9568.2005.04144.x

Christophe, A., Nespor, M., Teresa Guasti, M., and Van Ooyen, B. (2003). Prosodic structure and syntactic acquisition: the case of the head-direction parameter. Dev. Sci. 6, 211-220. doi: 10.1111/1467-7687.00273

Cooper, R. P., and Aslin, R. N. (1989). The language environment of the young infant: implications for early perceptual development. Can. J. Psychol. 43, 247-265. doi: 10.1037/h0084216

Cristia, A. (2013). Input to Language: the phonetics and perception of infantdirected speech. Lang. Linguist. Compass 7, 157-170. doi: 10.1111/lnc3.12015

de la Mora, D. M., Nespor, M., and Toro, J. M. (2013). Do humans and nonhuman animals share the grouping principles of the iambictrochaic law? Atten. Percept. Psychophys. 75, 92-100. doi: 10.3758/s13414-0120371-3

DeCasper, A. J., and Fifer, W. (1980). Of human bonding: newborns prefer their mothers' voices. Science 208, 1174-1176. doi: 10.1126/science.7375928

DeCasper, A. J., and Spence, M. J. (1986). Prenatal maternal speech influences newborns' perception of speech sounds. Infant Behav. Dev. 9, 133-150. doi: $10.1016 / 0163-6383(86) 90025-1$ a relatively late syntactic development vis $\grave{a}$ vis the prosodic development.

As a last remark, it should be noted that the globularization hypothesis-besides capturing the fact that prosodic knowledge precedes syntactic knowledge-also leaves room for explaining why first language acquisition is fast, but not immediate, for not all the necessary neurocognitive machinery would be established from birth (cf. Boeckx and Benítez-Burraco, 2014a,b). Even if innately specified, some maturation is in order for a fully language-ready brain.

\section{FUNDING}

This work was partially funded by the following agencies: the European Union's Seventh Framework Program (AThEME 613465), the Basque Government (IT769-13), and the Spanish MINECO (FFI2012-38064-C02-01, FFI2014-53675-P, FFI201341509-P).

Dehaene-Lambertz, G., and Baillet, S. (1998). A phonological representation in the infant brain. Neuroreport 9, 1885-1888. doi: 10.1097/00001756-19980601000040

Dehaene-Lambertz, G., Hertz-Pannier, L., Dubois, J., Mériaux, S., Roche, A., Sigman, M., et al. (2006). Functional organization of perisylvian activation during presentation of sentences in preverbal infants. Proc. Natl. Acad. Sci. U.S.A. 103, 14240-14245. doi: 10.1073/pnas.0606302103

Donegan, P. J., and Stampe, D. (1983). "Rhythm and the holistic organization of language structure," in Papers from the Parasession on the Interplay of Phonology, Morphology and Syntax, eds J. F. Richardson, M. Marks, and A. Chukerman (Chicago, IL: University of Chicago Press), 337-353.

Donegan, P. J., and Stampe, D. (2004). "Rhythm and the synthetic drift of munda," in The Yearbook of South Asian Languages and Linguistics 2004, eds U. N. Singh and S. Singh (Berlin; New York, NY: Mouton de Gruyter), 3-36.

Drullman, R., Festen, J. M., and Plomp, R. (1994). Effect of temporal envelope smearing on speech reception. J. Acoust. Soc. Am. 95, 1053-1064. doi: 10.1121/1.408467

Dubois, J., Poupon, C., Thirion, B., Simonnet, H., Kulikova, S., Leroy, F., et al. (2015). Exploring the early organization and maturation of linguistic pathways in the human infant brain. Cereb. Cortex. doi: 10.1093/cercor/bhv082. [Epub ahead of print].

Eimas, P. D., Siqueland, E. R., Jusczyk, P., and Vigorito, J. (1971). Speech perception in infants. Science 171, 303-306. doi: 10.1126/science.171.3968.303

Fernald, A. (1984). "The perceptual and affective salience of mothers' speech to infants," in The Origins and Growth of Communication, eds L. Feagans, R. M. Golinkoff, and C. Garvey (Norwood, NJ: Ablex), 5-29.

Fernald, A., and Mazzie, C. (1991). Prosody and focus in speech to infants and adults. Dev. Psychol. 27, 209-221. doi: 10.1037/0012-1649.27.2.209

Fifer, W. (1981). Early Attachment: Maternal-voice Preference in Oneand Three-day Old Infants. Ph.D. thesis, University of North Carolina, Greensboro, NC.

Fitch, W. T. (2013). Speech science: tuned to the rhythm. Nature 494, 434-435. doi: $10.1038 / 494434 \mathrm{a}$

Flaugnacco, E., Lopez, L., Terribili, C., Zoia, S., Buda, S., Tilli, S., et al. (2014). Rhythm perception and production predict reading abilities in developmental dyslexia. Front. Hum. Neurosci. 8:392. doi: 10.3389/fnhum.2014.00392

Gervain, J., and Werker, J. F. (2013). Prosody cues word order in 7-month-old bilingual infants. Nat. Commun. 4:1490. doi: 10.1038/ncomms2430

Ghazanfar, A. A., and Takahashi, D. Y. (2014). Facial expressions and the evolution of the speech rhythm. J. Cogn. Neurosci. 26, 1196-1207. doi: $10.1162 /$ jocn/a/00575

Giraud, A.-L., Kleinschmidt, A., Poeppel, D., Lund, T. E., Frackowiak, R. S., and Laufs, H. (2007). Endogenous cortical rhythms determine cerebral 
specialization for speech perception and production. Neuron 56, 1127-1134. doi: 10.1016/j.neuron.2007.09.038

Giraud, A.-L., and Poeppel, D. (2012). Cortical oscillations and speech processing: emerging computational principles and operations. Nat. Neurosci. 15, 511-517. doi: $10.1038 / \mathrm{nn} .3063$

Gleitman, L., and Wanner, E. (1982). "Language acquisition: the state of the art," in Language Acquisition: The State of the Art, eds E. Wanner and L. Gleitman (Cambridge: Cambridge University Press), 3-48.

Gordon, R. L., Shivers, C. M., Wieland, E. A., Kotz, S. A., Yoder, P. J., and Devin McAuley, J. (2015). Musical rhythm discrimination explains individual differences in grammar skills in children. Dev. Sci. 18, 635-644. doi: $10.1111 /$ desc. 12230

Goswami, U. (2011). A temporal sampling framework for developmental dyslexia. Trends Cogn. Sci. 15, 3-10. doi: 10.1016/j.tics.2010.10.001

Granier-Deferre, C., Bassereau, S., Ribeiro, A., Jacquet, A.-Y., and DeCasper, A. J. (2011). A melodic contour repeatedly experienced by human near-term fetuses elicits a profound cardiac reaction one month after birth. PLoS ONE 6:e17304. doi: 10.1371/journal.pone.0017304

Gunz, P., Neubauer, S., Golovanova, L., Doronichev, V., Maureille, B., and Hublin, J.-J. (2012). A uniquely modern human pattern of endocranial development. Insights from a new cranial reconstruction of the Neandertal newborn from Mezmaiskaya. J. Hum. Evol. 62, 300-313. doi: 10.1016/j.jhevol.2011. 11.013

Gussenhoven, C. (2004). The Phonology of Tone and Intonation. Cambridge; New York, NY: Cambridge University Press.

Hayes, B. (1995). Metrical Stress Theory: Principles and Case Studies. Chicago, IL: University of Chicago Press.

Hepper, P., Scott, D., and Shahidullah, S. (1993). Newborn and fetal response to maternal voice. J. Reprod. Infant Psychol. 11, 147-153. doi: $10.1080 / 02646839308403210$

Hepper, P. G., and Shahidullah, B. S. (1994). Development of fetal hearing. Arch. Disease Child. 71, F81-F87. doi: 10.1136/fn.71.2.F81

Iversen, J. R., Patel, A. D., and Ohgushi, K. (2008). Perception of rhythmic grouping depends on auditory experience. J. Acoust. Soc. Am. 124, 2263-2271. doi: $10.1121 / 1.2973189$

Jusczyk, P. W., and Nelson, D. G. K. (1996). "Syntactic units, prosody, and psychological reality during infancy," in Signal to Syntax: Bootstrapping from Speech to Grammar in Early Acquisition, eds J. L. Morgan and K. Demuth (Hillsdale: Lawrence Erlbaum), 389-410.

Karzon, R. G., and Nicholas, J. G. (1989). Syllabic pitch perception in 2- to 3-month-old infants. Percept. Psychophys. 45, 10-14. doi: 10.3758/BF03208026

Katz, G. S., Cohn, J. F., and Moore, C. A. (1996). A combination of Vocal fo dynamic and summary features discriminates between three pragmatic categories of infant-directed speech. Child Dev. 67, 205-217. doi: 10.1111/j.1467-8624.1996.tb01729.x

Kuhl, P. K., Andruski, J. E., Chistovich, I. A., Chistovich, L. A., Kozhevnikova, E. V., Ryskina, V. L., et al. (1997). Cross-language analysis of phonetic units in language addressed to infants. Science 277, 684-686. doi: $10.1126 /$ science. 277.5326 .684

Kuhl, P. K., and Miller, J. D. (1975). Speech perception by the chinchilla: voicedvoiceless distinction in alveolar plosive consonants. Science 190, 69-72. doi: $10.1126 /$ science. 1166301

Kuhl, P. K., Williams, K. A., Lacerda, F., Stevens, K. N., and Lindblom, B. (1992). Linguistic experience alters phonetic perception in infants by 6 months of age. Science 255, 606-608. doi: 10.1126/science.1736364

Lakatos, P., Shah, A. S., Knuth, K. H., Ulbert, I., Karmos, G., and Schroeder, C. E. (2005). An oscillatory hierarchy controlling neuronal excitability and stimulus processing in the auditory cortex. J. Neurophysiol. 94, 1904-1911. doi: 10.1152/jn.00263.2005

Langus, A., and Nespor, M. (2013). Language development in infants: what do humans hear in the first months of life? Hear. Balance Commun. 11, 121-129. doi: 10.3109/21695717.2013.817133

Leong, V. (2012). Prosodic Rhythm in the Speech Amplitude Envelope - Amplitude Modulation Phase Hierarchies (AMPHs) and AMPH Models. Ph.D. thesis, University of Cambridge, Cambridge.

Leong, V., and Goswami, U. (2014). Impaired extraction of speech rhythm from temporal modulation patterns in speech in developmental dyslexia. Front. Hum. Neurosci. 8:96. doi: 10.3389/fnhum.2014.00096
Leong, V., Kalashnikova, M., Burnham, D., and Goswami, U. (2014). "Infantdirected speech enhances temporal rhythmic structure in the envelope," in Proceedings of INTERSPEECH 2014 (Singapore), 2563-2567.

Lieberman, D. E., McBratney, B. M., and Krovitz, G. (2002). The evolution and development of cranial form in homo sapiens. Proc. Natl. Acad. Sci. U.S.A. 99, 1134-1139. doi: 10.1073/pnas.022440799

Mampe, B., Friederici, A. D., Christophe, A., and Wermke, K. (2009). Newborns' cry melody is shaped by their native language. Curr. Biol. 19, 1994-1997. doi: 10.1016/j.cub.2009.09.064

Martin, A., Schatz, T., Versteegh, M., Miyazawa, K., Mazuka, R., Dupoux, E., et al. (2014). Mothers speak less clearly to infants than to adults: a comprehensive test of the hyperarticulation hypothesis. Psychol. Sci. 26, 341-347. doi: 10.1177/ 0956797614562453

Martins, P. T., and Boeckx, C. (2014). Attention mechanisms and the mosaic evolution of speech. Front. Psychol. 5:1463. doi: 10.3389/fpsyg.2014.01463

Marx, V., and Nagy, E. (2015). Fetal behavioural responses to maternal voice and touch. PLoS ONE. 10:e129118. doi: 10.1371/journal.pone.0129118

Mehler, J. (1974). “Connaître par déssaprentisage," in Lunité de Lhomme II: Le Cerveau Humain, eds E. Morin and M. Piattelli-Palmarini (Paris: Editions du Seuil), 25-37.

Mehler, J., Bertoncini, J., and Barriere, M. (1978). Infant recognition of mother's voice. Perception 7, 491-497.

Mehler, J., and Dupoux, E. (1990). Naître Humain. Paris: Odile Jacob.

Mehler, J., Jusczyk, P., Lambertz, G., Halsted, N., Bertoncini, J., and Amiel-Tison, C. (1988). A precursor of language acquisition in young infants. Cognition 29, 143-178. doi: 10.1016/0010-0277(88)90035-2

Moffitt, A. R. (1971). Consonant cue perception by twenty- to twenty-four-weekold infants. Child Dev. 42, 717-731. doi: 10.2307/1127443

Molnar, M., Gervain, J., and Carreiras, M. (2014a). Within-rhythm class native language discrimination abilities of basque-spanish monolingual and bilingual infants at 3.5 months of age. Infancy 19, 326-337. doi: 10.1111/infa. 12041

Molnar, M., Lallier, M., and Carreiras, M. (2014b). The amount of language exposure determines nonlinguistic tone grouping biases in infants from a bilingual environment. Lang. Learn. 64, 45-64. doi: 10.1111/lang.12069

Morse, P. A. (1972). The discrimination of speech and nonspeech stimuli in early infancy. J. Exp. Child Psychol. 14, 477-492. doi: 10.1016/0022-0965(72)90066-5

Musacchia, G., Ortiz-Mantilla, S., Realpe-Bonilla, T., Roesler, C. P., and Benasich, A. A. (2015). Infant auditory processing and event-related brain oscillations. J. Vis. Exp. e52420. doi: 10.3791/52420

Nazzi, T., Bertoncini, J., and Mehler, J. (1998a). Language discrimination by newborns: toward an understanding of the role of the role of rhythm. J. Exp. Psychol. 24, 756-766. doi: 10.1037/0096-1523.24.3.756

Nazzi, T., Floccia, C., and Bertoncini, J. (1998b). Discrimination of pitch contours by neonates. Infant Behav. Dev. 21, 779-784. doi: 10.1016/S01636383(98)90044-3

Nazzi, T., Iakimova, G., Bertoncini, J., Frdonie, S., and Alcantara, C. (2006). Early segmentation of fluent speech by infants acquiring French: emerging evidence for crosslinguistic differences. J. Mem. Lang. 54, 283-299. doi: 10.1016/j.jml.2005.10.004

Nespor, M., Shukla, M., van de Vijver, R., Avesani, C., Schrauldolf, H., and Donati, C. (2008). Different phrasal prominence realizations in VO and OV languages. Lingue e Linguaggio VII-2, 139-168. doi: 10.1418/28093

Neubauer, S., Gunz, P., and Hublin, J.-J. (2010). Endocranial shape changes during growth in chimpanzees and humans: a morphometric analysis of unique and shared aspects. J. Hum. Evol. 59, 555-566. doi: 10.1016/j.jhevol.2010.06.011

Ockleford, E., Vince, M., Layton, C., and Reader, M. (1988). Responses of neonates to parents' and others' voices. Early Hum. Dev. 18, 27-36. doi: 10.1016/03783782(88)90040-0

Olsho, L. W., Schoon, C., Sakai, R., Turpin, R., and Sperduto, V. (1982). Auditory frequency discrimination in infancy. Dev. Psychol. 18, 721-726. doi: 10.1037/0012-1649.18.5.721

Pang, E. W., and Taylor, M. J. (2000). Tracking the development of the N1 from age 3 to adulthood: an examination of speech and non-speech stimuli. Clin. Neurophysiol. 111, 388-397. doi: 10.1016/S1388-2457(99)00259-X

Panneton, R., and Newman, R. (2012). "Development of speech perception," in Human Auditory Development, eds L. A. Werner, R. R. Fay, and A. N. Popper (New York, NY: Springer), 197-222. 
Paulescu, E., Déonet, J.-F., Fazio, F., McCrory, E., Chanoine, V., Brunswick, N., et al. (2001). Dyslexia: cultural diversity and biological unity. Science 291, 2165-2167. doi: 10.1126/science.1057179

Peña, M., Maki, A., Kovacic, D., Dehaene-Lambertz, G., Koizumi, H., Bouquet, F., et al. (2003). Sounds and silence: an optical topography study of language recognition at birth. Proc. Natl. Acad. Sci. U.S.A. 100, 11702-11705. doi: 10.1073/pnas.1934290100

Peelle, J. E., and Davis, M. H. (2012). Neural oscillations carry speech rhythm through to comprehension. Lang. Sci. 3:320. doi: 10.3389/fpsyg.2012.00320

Pfau, R., and Quer, J. (2010). "Nonmanuals: their grammatical and prosodic roles," in Sign Languages, ed D. Brentari (Cambridge: Cambridge University Press), 381-402.

Querleu, D., Lefebvre, C., Titran, M., Renard, X., Morillion, M., and Crepin, G. (1984). Reaction of the newborn infant less than 2 hours after birth to the maternal voice. J. Gynecol. Obstet. Biol. Reprod. 13, 125-134.

Ramus, F., Hauser, M. D., Miller, C., Morris, D., and Mehler, J. (2000). Language discrimination by human newborns and by cotton-top tamarin monkeys. Science 288, 349-351. doi: 10.1126/science.288.5464.349

Rebuschat, P., Rohrmeier, M., Hawkins, J. A., and Cross, I., (eds.). (2011). Language and Music as Cognitive Systems. Oxford: Oxford University Press.

Sansavini, A., Bertoncini, J., and Giovanelli, G. (1997). Newborns discriminate the rhythm of multisyllabic stressed words. Dev. Psychol. 33, 3-11. doi: 10.1037/0012-1649.33.1.3

Saralegui, I., Ontañón, J. M., Fernandez-Ruanova, B., Garcia-Zapirain, B., Basterra, A., and Sanz-Arigita, E. J. (2014). Reading networks in children with dyslexia compared to children with ocular motility disturbances revealed by fMRI. Front. Hum. Neurosci. 8:936. doi: 10.3389/fnhum.2014.00936

Selkirk, E. (2011). "The syntax-phonology interface," in The Handbook of Phonological Theory, 2nd Edn., eds J. Goldsmith, J. Riggle, and A. C. L. Yu (Oxford: Wiley-Blackwell), 435-484.

Shahidullah, S., and Hepper, P. G. (1994). Frequency discrimination by the fetus. Early Hum. Dev. 36, 13-26. doi: 10.1016/0378-3782(94)90029-9

Shukla, M., and Nespor, M. (2010). "Rhythmic patterns cue word order," in The Sound Patterns of Syntax, eds N. Erteschik-Shir and L. Rochman (Oxford: Oxford University Press), 174-188.

Smith, Z. M., Delgutte, B., and Oxenham, A. J. (2002). Chimaeric sounds reveal dichotomies in auditory perception. Nature 416, 87-90. doi: 10.1038/416087a

Spence, M. J., and DeCasper, A. J. (1987). Prenatal experience with lowfrequency maternal-voice sounds influence neonatal perception of maternal voice samples. Infant Behav. Dev. 10, 133-142. doi: 10.1016/0163-6383(87) 90028-2

Telkemeyer, S., Rossi, S., Koch, S. P., Nierhaus, T., Steinbrink, J., Poeppel, D., et al. (2009). Sensitivity of newborn auditory cortex to the temporal structure of sounds. J. Neurosci. 29, 14726-14733. doi: 10.1523/JNEUROSCI.1246-09.2009

Telkemeyer, S., Rossi, S., Nierhaus, T., Steinbrink, J., Obrig, H., and Wartenburger, I. (2011). Acoustic processing of temporally modulated sounds in infants: evidence from a combined near-infrared spectroscopy and EEG study. Lang. Sci. 1:62. doi: 10.3389/fpsyg.2011.00062
Theofanopoulou, C. (2015). Brain asymmetry in the white matter making and globularity. Front. Psychol. 6:1355. doi: 10.3389/fpsyg.2015.01355

Toro, J. M., Trobalon, J. B., and Sebastián-Gallés, N. (2003). The use of prosodic cues in language discrimination tasks by rats. Anim. Cogn. 6, 131-136. doi: 10.1007/s10071-003-0172-0

Truckenbrodt, H. (2007). "The syntax-phonology interface," in The Cambridge Handbook of Phonology, ed P. de Lacy (Cambridge: Cambridge University Press), 435-456.

VanRullen, R., and Dubois, J. (2011). The Psychophysics of brain rhythms. Front. Psychol. 2:203. doi: 10.3389/fpsyg.2011.00203

Vihman, M. M. (2014). Phonological Development: The First Two Years, 2 Edn. Malden, MA; Oxford: Wiley Blackwell.

Vince, M. A. (1979). Postnatal effects of prenatal sound stimulation in the guinea pig. Anim. Behav. 27, 908-918. doi: 10.1016/0003-3472(79)90029-0

Vince, M. A., Armitage, S. E., Walser, E. S., and Reader, M. (1982). Postnatal consequences of prenatal sound stimulation in the sheep. Behaviour 81, 128-139. doi: 10.1163/156853982X00111

Wahl, M., Marzinzik, F., Friederici, A. D., Hahne, A., Kupsch, A., Schneider, G.-H. et al. (2008). The human thalamus processes syntactic and semantic language violations. Neuron 59, 695-707. doi: 10.1016/j.neuron.2008.07.011

Wang, L., Uhrig, L., Jarraya, B., and Dehaene, S. (2015). Representation of numerical and sequential patterns in macaque and human brains. Curr. Biol. 25, 1966-1974. doi: 10.1016/j.cub.2015.06.035

Ward, C. D., and Cooper, R. P. (1999). A lack of evidence in 4-month-old human infants for paternal voice preference. Dev. Psychobiol. 35, 49-59. doi: 10.1002/(SICI)1098-2302(199907)35:1<49::AID-DEV7>3.0.CO;2-3

Werker, J. F., and Tees, R. C. (2002). Cross-language speech perception: evidence for perceptual reorganization during the first year of life. Infant Behav. Dev. 25, 121-133. doi: 10.1016/S0163-6383(02)00093-0

Zumbansen, A., Peretz, I., and Hébert, S. (2014). The combination of rhythm and pitch can account for the beneficial effect of melodic intonation therapy on connected speech improvements in Brocas aphasia. Front. Hum. Neurosci. 8:592. doi: $10.3389 /$ fnhum.2014.00592

Conflict of Interest Statement: The author declares that the research was conducted in the absence of any commercial or financial relationships that could be construed as a potential conflict of interest.

The reviewer, Silvia Martínez Ferreiro, and handling editor, Cedric Boeckx, declared their shared affiliation, and the handling editor states that the process nevertheless met the standards of a fair and objective review.

Copyright (C) 2015 Irurtzun. This is an open-access article distributed under the terms of the Creative Commons Attribution License (CC BY). The use, distribution or reproduction in other forums is permitted, provided the original author(s) or licensor are credited and that the original publication in this journal is cited, in accordance with accepted academic practice. No use, distribution or reproduction is permitted which does not comply with these terms. 